\title{
EFECTO DEL ACIDO INDOLBUTIRICO (IBA) Y 6-BENCILAMINOPURINA (BAP) EN EL DESARROLLO IN VITRO DE YEMAS AXILARES DE ENCYCLIA MICROTOS (RCHB.F.) HOEHNE (ORCHIDACEAE)
}

\author{
Carlos E. Condemarín-Montealegre ${ }^{1}$, Julio Chico-Ruíz \& Claudia Vargas-Artaega \\ Laboratorio de Fisiología y Cultivo de Tejidos Vegetales. Facultad de Ciencias Biológicas \\ Universidad Nacional de Trujillo. Av. Juan Pablo II s/n-San Andrés. Trujillo-Perù \\ 1'Author for correspondence: kaiki_conde@hotmail.com
}

\begin{abstract}
Encyclia microtos (Rchb.f.) Hoehne, is an endemic orchid that are distributed in the north of Peru (Tumbes and Piura) and it is being depredy illegally causing the extinction of the same one. With interest to maintain his conservation, is an alternative by means of the propagation in vitro. For that reason the objective of this research is to evaluate the indolbutiric acid effect (AIB) and 6-bencilaminopurine (BAP) in the development in vitro of axillar bud of $E$. microtos. The experience with plant of 120 days of age began, it was introduced in medium MS (Murashige and Skoog) suplement with sucrose, phytagel, AIB , BAP (single or combined) and adjusting to $\mathrm{pH}$ of 5.5. Nine treatments were made, in a rank of $0 ; 1$ and $2 \mathrm{ppm}$ (single or combined). The results showed that BAP (2 ppm) promoted the greater development of axillary buds with a rate of multiplication of the double of plant to the 90 days in which they were exposed to the growth regulators. To single concentrations of AIB (1 ppm and $2 \mathrm{ppm})$, promoted a better development of leaves, roots and length of the same ones.
\end{abstract}

KEY WoRDS: in vitro axillar bud, Encyclia microtos, AIB, BAP

\section{Introducción}

La familia Orchidaceae, está constituido aproximadamente por 17000 a 35000 especies $(40 \%$ de las monocotiledóneas) y es la más extensa de las angiospermas, ocupan un amplio rango de los hábitats ecológicos, son las más evolucionada debido a que han desarrollado un gran potencial morfogenético, fisiológico y estructural, debido a muchas estructuras reproductivas condicionadas por la alta totipotencialidad de sus células. Estos sistemas reproductivos difieren en gran medida en diferentes zonas de temperatura, clima, etc, las cuales permite adaptarse y determinan su estrategia de supervivencia, lo cual explica su amplia área de distribución (Rasmussen 1985, Dressler 1993, Batygina et al. 2003).

El género Encyclia fue establecido por Hookern en 1828 , son generalmente epífitas, endémicas del continente americano, se extiende desde el sur de Méjico hasta la parte norte de América del Sur. Encyclia microtos (Reichb.f.) Hoehne 1952, es una especie epífita con un período floral de diciembre a febrero, es endémica del sur del Ecuador y el norte del Perú, desde el bosque seco de Tumbes hasta el bosque de Cuyas en Piura. (Bennett \& Christenson 1993).

De acuerdo a los estudios de Bennett y Christenson (1993), Juergen et al. (1996), Díaz (2003) y Fernández (2002) el Perú tiene alrededor de tres mil especies de orquídeas, distribuidas de Tumbes a Puno. La mayor diversidad se concentra en la ceja de selva, comprendida entre los 500 y 3,600 m.s.n.m. La menor diversidad corresponde a la selva baja (entre los 300 m.s.n.m.) y la serranía entre los 2,600 y 3,600 m.s.n.m. Más de la mitad de las orquídeas son epífitas, las cuales contribuyen con el $11 \%$ de las 17 mil especies de angiospermas peruanas. Se calcula aún que existen muchas más especies nuevas sobretodo en las zonas remotas e inaccesibles del país así como en las cordilleras aisladas. Las orquídeas denotan un alto grado de endemismo lo cual los hace más vulnerables debido a la destrucción de sus hábitats por la quema y tala de los bosques de la agricultura itinerante.

Desde el desarrollo del método de germinación asimbiótica en semillas de orquídeas por Knudson (1946), las técnicas de cultivo han sido usadas para la 
propagación a gran escala de muchas especies de orquídeas y sus híbridos (Rao 1977, Arditti \& Ernst 1993). Esto ha llevado a muchas firmas comerciales a usar el sistema in vitro por la rapidez de su propagación masiva (Teixeira 2003). Estas técnicas han mostrado resultados poco exitosos en nuestro país, limitándose a la extracción y comercialización directa en el campo, lo cual reduce significativamente el número de éstas en su hábitat, por lo tanto es necesario establecer pautas muy claras y precisas acerca de su conservación o manejo sostenible, puesto que constituyen uno de nuestros patrimonios nacionales (Morel 1974, Teng et al. 1997, Torres \& Mogollón 2000, Decrose et al. 2003, Calatayud 2004, Puchooa 2004),

Las auxinas participan en muchos procesos del desarrollo vegetal: crecimiento, dominancia apical, enraizamiento, partenocarpia, tropismos, abscisión, elongación celular y frecuentemente en embriogénesis y organogénesis en cultivos en suspención. Uno de los reguladores más utilizados en la formación de raíces es el ácido indolbutírico (IBA) debido a que no causa efectos fitotóxicos, ni inhibe el crecimiento caulinar (Pierik 1990, Salisbury \& Ross 2000).

Las citoquininas estimulan la división y diferenciación celular que afecta a una amplia gama de procesos de crecimiento y desarrollo de las plantas, entre lo que cabe citar la iniciación del desarrollo del cloroplasto, fotosíntesis, la expansión de los cotiledones, así como la inducción de la formación de brotes en cultivo vegetales. (Salisbury \& Ross 2000, AscónBieto \& Talon 2001, Martinez 2002).

El uso de reguladores de crecimiento como alternativa para el incremento de la proliferación de brotes directos han probado la influencia de diferentes dosis de auxinas y citoquininas en el medio de cultivo basal Murashige y Skoog (1962) en diferentes géneros como Cattleya aurantiaca (Mauro 1994, Torres \& Mogollón 2000, Krapiec et al. 2003), Cymbidium aloifolium, Dendrobium aphyllum y Dendrobium moschatum (Nayak et al. 1997), Phalaenopsis sp (Kosir et al. 2004), Vanda spathulata (Decrose et al. 2003), Catasetum fimbriatum (Peres et al. 2001), entre otros.

Nuestras especies nativas de orquídeas, amenazadas o en peligro de desaparecer, pueden protegerse utilizando las técnicas de propagación masiva in vitro, siempre y cuando se asegure su reproducción en cantidades adecuadas. Las plantas propagadas podrían distribuirse a viveros comerciales, lo que produciría una disminución de la extracción ilegal en sus hábitats naturales; asimismo, podrían ser reintroducidas a los hábitats en los que ha desaparecido completamente (León, 1995). El interés por las orquídeas si bien son apreciadas por sus vistosos colores, formas de sus flores y por la durabilidad de las mismas; son plantas que requieren de condiciones especiales para la germinación de las semillas y de períodos vegetativos largos antes de su floración, las cuales son necesarias diferentes técnicas para su propagación. Conociendo esta realidad, el objetivo de este trabajo es reconocer el efecto de ácido indolbutírico (IBA) y BAP en el desarrollo de yemas axilares en plántulas de Encyclia microtos (Reichb.f.) Hoehne (Orchidaceae).

\section{Material y métodos}

Material Biologico. La especie E. microtos fue determinada en el Herbarium Truxillense (HUT) de la Universidad Nacional de Trujillo (Perú). La experiencia se desarrolló en el laboratorio de Fisiología y Cultivos de Tejidos Vegetales de la Universidad Nacional de Trujillo, las cuales proporcionó las plántulas de E. microtos (fig. 1) en condiciones in vitro y de 120 días de edad (fig. 2).

Diseño ExPerimental. El medio nutritivo basal usado fué el de Murashige y Skoog (MS) (1962), vitaminas como mio-inositol $20 \mathrm{gl}^{-1}$; ácido nicotínico $0,1 \mathrm{gl}^{-1}$; piridoxina-HCl $0,1 \mathrm{gl}^{-1}$; tiamina-HCl 0,1 $\mathrm{gl}^{-1}$; glicina $0,1 \mathrm{gl}^{-1}$; las que fueron suplementadas con IBA y bencilaminopurina (BAP), sacarosa (3\%), fitagel $(0,25 \%)$ y ajustándose a un $\mathrm{pH}$ de 5,5 . Los diferentes tratamientos tuvieron las siguientes combinacines de IBA y BAP:

Reguladores de crecimiento

\begin{tabular}{cc}
\hline Tratamientos & IBA x BAP \\
\hline $\mathrm{T} 1$ & $0.0 \times 0.0$ \\
\hline $\mathrm{T} 2$ & $1.0 \times 0.0$ \\
\hline $\mathrm{T} 3$ & $2.0 \times 0.0$ \\
\hline $\mathrm{T} 4$ & $0.0 \times 1.0$ \\
\hline $\mathrm{T} 5$ & $1.0 \times 1.0$ \\
\hline $\mathrm{T} 6$ & $2.0 \times 1.0$ \\
\hline $\mathrm{T} 7$ & $0.0 \times 2.0$ \\
\hline $\mathrm{T} 8$ & $1.0 \times 2.0$ \\
\hline $\mathrm{T} 9$ & $2.0 \times 2.0$
\end{tabular}




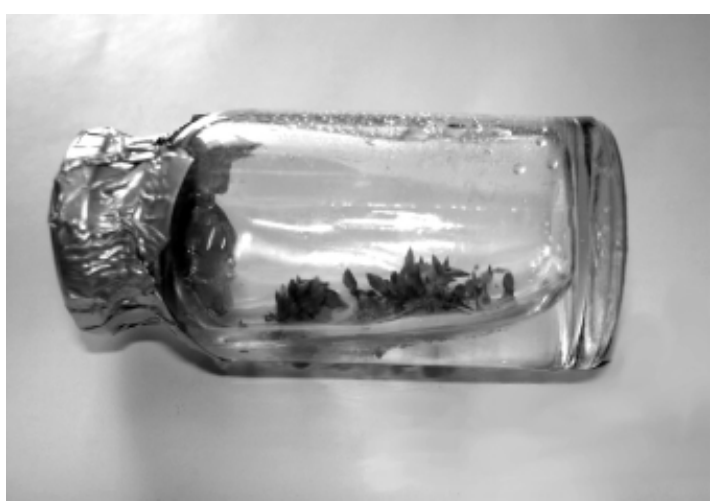

FiguRA 1. Plántulas in vitro de E. microtos de 120 días de edad.

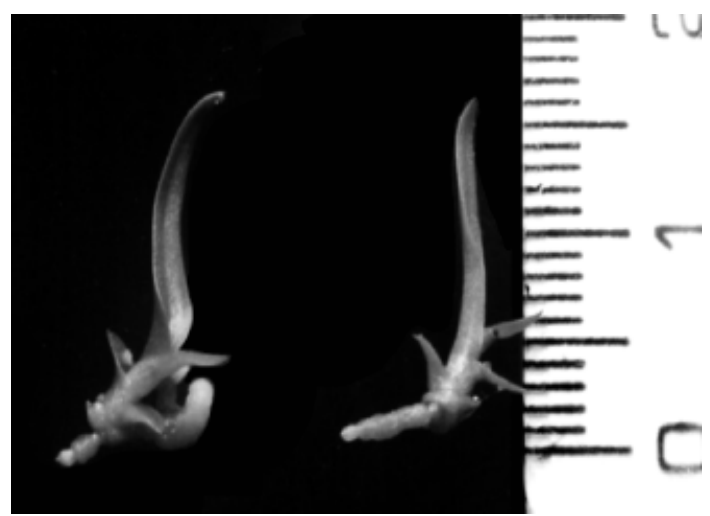

FiguRA 2. Plántulas de E. microtos usados como explantes que fueron expuestos a diferentes concentraciones de IBA y BAP, para inducir el desarrollo de yemas axilares.

El volumen de $2 \mathrm{ml}$ de medio de cultivo se colocó en frascos de vidrio, las cuales fueron sellados con papel de aluminio, y posteriormente autoclavado a $120^{\circ} \mathrm{C}$ por 15 minutos.

Se utilizó una cámara aséptica para realizar el proceso de introducción de las plántulas en los fras- cos de vidrio (una plántula por frasco, diez plántulas por tratamiento), luego se llevaron a la sala de incubación y fueron colocados en un estante metálico donde recibieron fuente luminosa proporcionada por tres fluorescentes de luz blanca ( $40 \mathrm{w})$ y con un fotoperíodo de 16:8 y una temperatura promedio de $25^{\circ} \mathrm{C}$

La evaluación se realizó cada 30 días durante tres meses y se anotaron los siguientes datos: presencia y número de desarrollo de yemas axilares, número de hojas, número y longitud de raíces las cuales fueron sometidos a análisis estadísticos: promedios, análisis de varianza, tasa de multiplicación y prueba de significación Tukey con un nivel de significancia de 0,05 .

\section{Resultados}

Todos los tratamientos ensayados, mostraron diferencias significativas (ANAVA, significancia $95 \%$ ), y el mejor tratamiento resultó ser BAP (2 ppm) comprobado con la prueba de rangos estandarizados de Tukey con un nivel de significancia al 95\% (tablas 1 y 2 ).

El desarrollo de yemas axilares fueron a los 30 días de ser expuestas a los reguladores de crecimiento. Se observó un mayor desarrollo de yemas axilares a concentraciones de 2 ppm de BAP obteniéndose en promedio el doble de plántulas, a la vez también se observó un mayor desarrollo de 1.8 plántulas concentraciones combinadas de 2 ppm de IBA con 2 ppm de BAP durante los 90 días expuestos a los reguladores de crecimiento y un menor desarrollo a $2 \mathrm{ppm}$ de IBA aumentando sólo a 1.13 plántulas desarrolladas en promedio (fig. 3).

TABLA 1. Análisis de varianza para el número de brotes obtenidos a partir de yemas axilares de E. microtos a los 90 días de ser sometidas a diferentes concentraciones de IBA y BAP.

\begin{tabular}{l|c|c|c|c|c} 
F de V & GL & Sum. de Cuad & Cuad. Med & Coef. F & P-valor \\
\hline AIB & 2 & 1.17037 & 0.5851850. & 16 & 0.3178 \\
\hline BAP & 2 & 6.05926 & 3.02963 & 5.99 & $0.0033 *$ \\
\hline AIB x BAP & 4 & 2.6963 & 0.674074 & 1.33 & 0.2615 \\
\hline Residuos & 126 & 63.7333 & 0.50582 & & \\
\hline Total & 73.6593 & 134 & & & \\
\hline
\end{tabular}

* P-valor inferior a 0.05 (BAP), efecto estadísticamente significativo en el número de brotes para un $95.0 \%$. 
TABLA 2. Tukey para el número de yemas axilares de $E$. microtos según BAP.

\begin{tabular}{l|c|c} 
BAP & diferencias & +/- límites \\
\hline $1 \mathrm{ppm}$ & -0.33333 & 0.355617 \\
\hline $2 \mathrm{ppm}$ & $*-0.51111$ & 0.355617 \\
\hline BAP x IBA & -0.17777 & 0.355617 \\
\hline
\end{tabular}

Diferencia significativa para el número de brotes a un nivel de significancia de $95.0 \%$.

Un mayor aumento a 1.8 hojas por plántula en promedio, se observó a 2 ppm de IBA en comparación con los demás tratamientos en que no se observó una diferencia significativa (fig. 4).

En relación al número de raíces se observó un incremento de 2.56 raíces a $1 \mathrm{ppm}$ de IBA y un 2.29 raíces a 2 ppm de IBA y menos efectivo fue a concentraciones combinadas de $1 \mathrm{ppm}$ de IBA con 1 ppm de BAP aumentando sólo 1.18 raíces
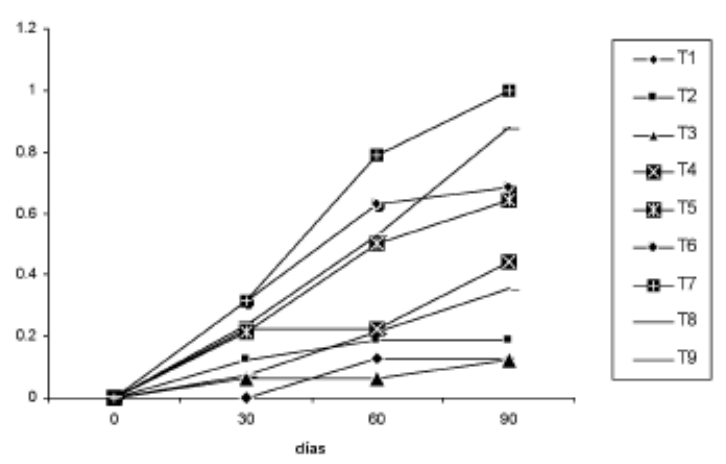

Figura 3. Número de yemas axilares en plántulas de $E$. microtos a los 120 días de edad y sometidos a diferentes concentraciones de IBA y BAP.
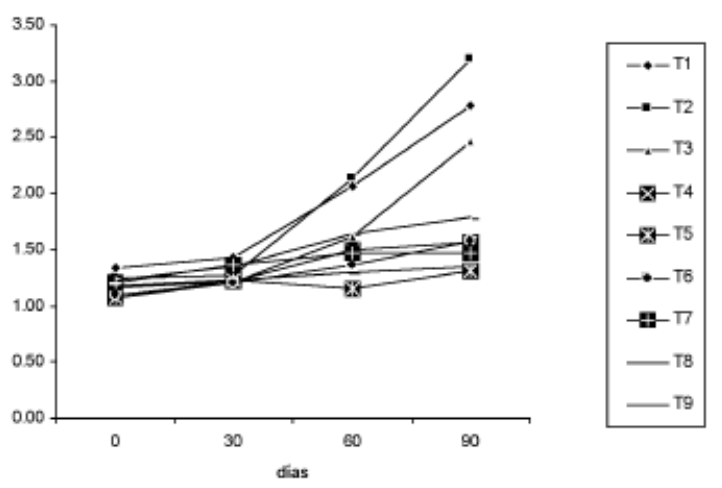

FigurA 5. Número de raíces en plántulas de E. microtos a los 120 días de edad y sometidos a diferentes concentraciones de IBA y BAP. en promedio (fig. 5).

Para la longitud de raíces hubo un mayor desarrollo a concentraciones solas de $1 \mathrm{ppm}$ y $2 \mathrm{ppm}$ de IBA aumentado a $4.19 \mathrm{~mm}$ y $3.65 \mathrm{~mm}$ en promedio respectivamente. En los demás tratamientos se observó una menor desarrollo en la longitud de raíz se observó a 2 ppm de BAP aumentando sólo $0.39 \mathrm{~mm}$ (fig. 6).

\section{Discusión}

Los resultados obtenidos muestran que a $2 \mathrm{ppm}$ de BAP, desarrollaron un mayor número de yemas axilares, en comparación a las otras concentraciones (fig. 3). Esto concuerda con Kosir et al. (2004), que reporta un mayor desarrollo de yemas a concentraciones altas de BAP en Phalaenopsis sp. usando nudos como explantes. Este tipo de regeneración podría mejorar la multiplicación masal a niveles comerciales, ya que reduce signi-

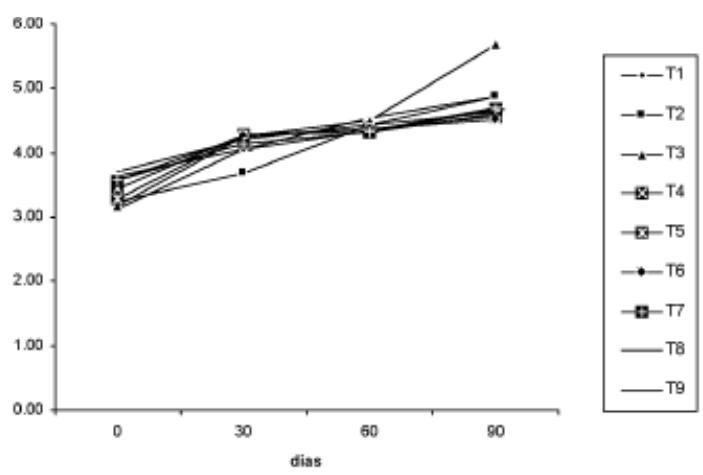

Figura 4. Número de hojas en plántulas de E. microtos a los 120 días de edad y sometidos a diferentes concentraciones de IBA y BAP.

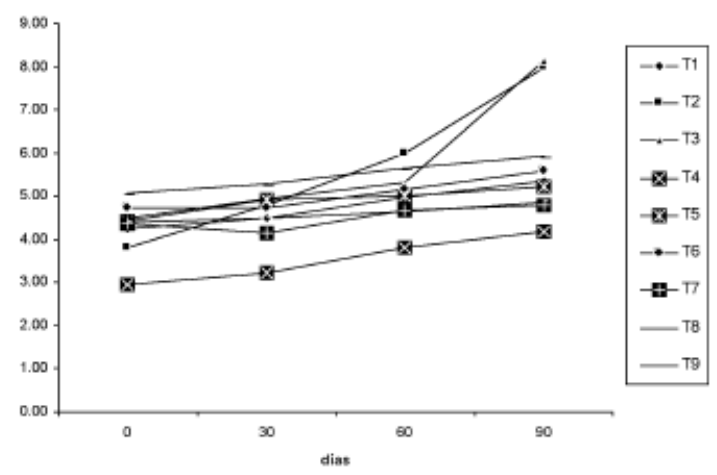

Figura 6. Longitud de raíz en plántulas de E. microtos a los 120 días de edad y sometidos a diferentes concentraciones de IBA y BAP. 
ficativamente la variabilidad somaclonal originado por la formación de callos. Pierik (1990), sostiene que BAP a mayores concentraciones estimulan la división celular propiciando el crecimiento y desarrollo de nuevos tejidos, promoviendo la formación de yemas axilares, ya que disminuye la dominancia apical, iniciando así una descendencia homocigota idéntica a la planta madre. Además, esta citoquinina (BAP), regula muchos aspectos en el desarrollo de las plantas, incluyendo la división celular, neoformación de órganos, desarrollo de cloroplastos y senescencia (Ascon-Bieto \& Talon 2001).

A concentraciones combinadas de $2 \mathrm{ppm}$ de IBA y 2 ppm de BAP (T9), se observó un mayor número de brotes axilares, debido al efecto sinérgico entre estos dos reguladores (Pierik 1990, Hurtado \& Merino 1994), Estos resultados coinciden con Krapiec et al. (2003), quienes lograron incrementar gradualmente un número mayor de brotes directos en Cattleya walkeriana, usando las mismas concentraciones de IBA y BAP en 90 días de estudio. Estos datos obtenidos estarían relacionados a un desencadenamiento fisiológico de la acción hormonal, condicionado por la aplicación e interacción de los reguladores de crecimiento exógenos, por las dosificaciones de las hormonas al medio, como también por la capacidad de absorción de los tejidos por difusión, como lo reporta Chico et al., (2002), en segmentos nodales de Vitis vinifera var. "borgoña" expuestos a diferentes concentraciones de BAP y ácido naftalenacético (ANA).

La biosíntesis, conjugación, oxidación, transporte y efectos de auxinas y citoquininas sobre el órgano de crecimiento, se postula que son las raíces las principales zonas de biosíntesis de citoquininas y las exporta hacia los brotes, donde se promueve su desarrollo (caulogénesis). Inversamente, los brotes son considerados como la principal fuente de biosíntesis de auxinas, lo cual pueden ser inactivados por la conjugación y/o oxidación, tan bien como son exportadas hacia las raíces. Los brotes derivados de auxinas puede promover la iniciación y crecimiento de raíces (rizogénesis) (Peres et al. 2001), promoviendo a la vez la domi- nancia apical, la cual ejerce el control del ápice caulinar sobre el crecimiento de las yemas laterales. Se postula que el ápice caulinar reprime el crecimiento de las yemas axilares actuando como un sumidero, activado por la auxina, para la citoquininas derivadas de la raíz, lo que limitaría el transporte de las citoquininas hacia las yemas laterales (Ascon-Bieto \& Talon 2001). Como las raíces de las orquídeas epífitas tienen algunos aspectos característicos, por ejemplo, la acumulación de clorofila y geotropismo negativo, las cuales pueden tener una considerable capacidad de biosíntesis de auxina, esto se observó que a concentraciones de 1 ppm y 2 ppm de IBA presenta un menor número de desarrollo de yemas axilares y mayor formación de raíces. Este desbalance, entre la formación de vástagos y raíces con concentraciones de citoquininas o auxinas, lo explica Peres et al. (2001), en plantas transgénicas expresando el gen ipt de Agrobacterium tumefaciens, lo cual presenta un aumento en la biosíntesis de citoquininas, en consecuencia, incrementó la formación de vástagos y la inhibición en la iniciación de raíces; contrariamente en plantas transgénicas expresando los genes biosintéticos de auxinas (iaaM y $i a a H)$, tendieron a presentar una sustancial formación de raíces y la inhibición en el desarrollo de brotes axilares.

Salisbury y Ross (2001) resalta que el IBA se utiliza para causar la formación de raíces aún más a menudo que ANA o cualquier otra auxina. El IBA es activo pese a que se metaboliza con rapidez a IBA-aspartato y al menos otro compuesto conjugado con un péptido. Se ha sugerido que la formación de conjugado almacena al IBA y que su liberación gradual mantiene niveles adecuados de concentración de IBA, especialmente es las etapas finales de la formación de la raíz. Esto se comprueba con la figura 4, 5 y 6 , en las cuales, el uso de IBA, promueve el enraizamiento y desarrollo de hojas a concentraciones de $1 \mathrm{ppm}$ y $2 \mathrm{ppm}$, sin combinar ya que induce la elongación celular en las células de las raíces y promueve la dominancia apical. Sin embargo, BAP solo o combinado ofrece un efecto inhibitorio en la elongación de la raíz como lo reporta Collie y Kerbauy (1993) en Catasetum sp. 
y otras especies de orquídeas. Este desarrollo vegetativo efectivo en las plántulas usando IBA como regulador de crecimiento coincide con Krapiec et al. (2003) en plántulas de Cattleya walkeriana, obteniéndose plántulas morfológicamente similares a las plantas adultas.

La mayoría de especies de orquídeas tienen la capacidad de propagación vegetativa, variando en los patrones de reproducción, esto se evidencia desde los estadios de protocormo, germinación de yemas apicales y axilares incluyendo las dormantes, órganos axilares como los rizomas, además los tallos, hojas, inflorescencias que también son usadas como explantes (Batygina et al. 2003, Puchooa 2004).

Algunos autores han usado nudos con yemas como explantes combinando incluso BAP y auxinas como ANA para aumentar la proliferación de brotes en Cattleya aurantiaca (Mauro et al. 1994), thidiazurón (TDZ) y ANA en Cymbidium aloifolium, Dendrobium aphyllum y Dendrobium moschatum (Nayak et al. 1997), bencilaminoadenina (BA) y ácido indolacético (AIA) en Vanda spathulata (Decrose et al, 2003), AIA y zeatina (Z) en Catasetum sp. (Peres et al., 2001), y usando solamente TDZ en ápices caulinares en Cattleya mossiae y la proliferación de brotes directos sin la formación previa de callos. La regeneración directa sin la indeseable formación de callos acorta el período de tiempo necesario para la regeneración y reducción de la posible incidencia de variación somaclonal (Kosir et al. 2004). Sin embargo, los mayores logros in vitro de orquídeas ha sido más frecuente en la proliferación de cuerpos protocórmicos a partir de callos usando diferentes partes de la planta como explantes en diferentes combinaciones de reguladores de crecimiento (Arditti \& Ernst 1993. De Pauw et al. 1995. Teng et al. 1997, Young et al. 2000. Tokuhara \& Mii 2001. Chen et al. 2002. Chen \& Chang 2002. Puchooa 2004, Nagaraju \& Mani 2005).

El establecimiento de esta simple técnica efectiva de propagación directa de yemas, evitando la variación somaclonal, podría mejorar la producción a escala comercial o también para la conservación ex situ, creando bancos de germoplasma de especies amenazadas en un corto período de tiem-

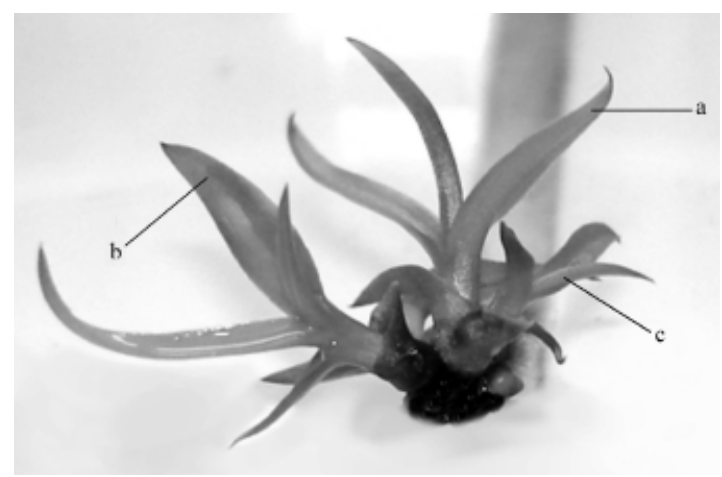

FigurA 7. Planta madre (a) de E. microtos con el desarrollo de 2 yemas axilares (b y c) a los 90 días expuestos a BAP.

po en especies de orquídeas.

\section{Conclusiones}

BAP a concentraciones de 2 ppm y combinados IBA (2 ppm) con BAP (2 ppm), fueron los que promovieron el mayor desarrollo de yemas axilares obteniéndose una tasa de multiplicación del doble de plántulas y 1.8 plántulas respectivamente .

IBA a concentraciones de 1 ppm y 2 ppm, promovieron un mejor desarrollo de hojas ( 1.8 hojas en promedio a $1 \mathrm{ppm})$, formación de nuevas raíces $(2.56 \mathrm{y}$ 2.29 raíces en promedio a $1 \mathrm{ppm}$ y 2 ppm respectivamente) y longitud de raíces ( $4.19 \mathrm{~mm}$ y $3.65 \mathrm{~mm}$ en promedio a $1 \mathrm{ppm}$ y $2 \mathrm{ppm}$ respectivamente) en $E$. microtos (fig. 7).

\section{LITERATURA CITADA}

Arditti, J. \& R. Ernst. 1993. Micropropagation of Orchids. John Wiley and Sons. New York.

Ascon-Bieto, J. \& M. Talon. 2001. Fundamentos de Fisiología Vegetal. Edit. Interamericana. Mc Graw-Hill. Madrid

Batygina, T., E. Bragina \& V. Vasilyeva. 2003. The Reproductive System and Germination in Orchids. Acta Biologica Cracoviensia. Series Botanica 45 (2): 21-34.

Benett, D. \& E.A. Christenson. 1993. Icones Orchidacearum Peruvianum. Plates 1-200.

Kafkafi, U (ed.). Plant roots the hidden half. New York, Marcel Dekker. p. 875-894.

Calatayud, G. 2004. Diversidad de Orchidaceae en los bosques de la provincia San Ignacio (Cajamarca). Libro de Resúmenes del X Congreso Nacional de Botánica. Trujillo, Perú. 
Chen, L., J. Chen \& W. Chang. 2000. Efficient production of protocorm-like bodies and plant regeneration from flower stalk explants of the sympodial orchid Epidendrum radicans. In Vitro Cell. Dev. Biol. Plant 38: 441-445.

Chen, J. \& W. Chang. 2002. Effects of tissue culture conditions and explant characteristics on direct somatic embryogenesis in Oncidium 'GowerRamsey'. Plant Cell Tissue. Organ Cult. 69: 41-44.

Chico, J., L. Cerna, R. Veneros, B. Valentin \& M. Bobadilla. 2002. Propagación in vitro de Vitis vinfera var. borgoña. Rebiol 22 (1-2): 1-6.

Collie, S. \& G. Kerbauy. 1993. Direct root tip conversion of Catasetum into protocorm-like bodies. Effect auxin and cytokinin. Plant Cell, Tissue and Organ Culture. 33: 39-44.

De Pauw, M., W. Remphrey \& C. Palmer. 1995. The Cytokinin Preference for in vitro germination and protocorm growth of Cypripedium candidum. Annals of Botany. 75: 267-275.

Decrose, W., A. Gangaprasad, S. Seeni \& S. Menon. 2003. Micropropagation and ecorestation of Vanda spathulata, an exquisite orchid. Plant Cell, Tissue and Organ Culture. 72: 199-202.

Díaz, M. 2003. Orquídeas del bosque de Cuyas (Ayabaca), Piura-Perú. Tesis para optar el Título de Biólogo. Universidad Nacional de Piura. Perú

Dressler, R.L. 1993. Phylogeny and classification of the orchid family. Portland, Oregon, Dioscorides Press: 314318.

Fernández, R. 2002. Estudio de Orquídeas del Perú. Libro de Resúmenes de IX Congreso Nacional de Botánica. Pag 86. Universidad Nacional de la Amazonía.

Hurtado, D. \& M. Merino. 1994. Cultivo de Tejidos Vegetales. Edit. Trillas. Mexico.

Juergen, N., L. Ibisch \& W. Barthlott. 1996. Biodiversidad de epífitas - una cuestión de escala. Revista Jardín Botánico Nacional.

Kosir, P., S. Skof \& Z. Luthar. 2004. Direct shoot regeneration from nodes of Phalaenopsis orchids. Acta Agriculturae Slovenica, 83(2): 233 - 242.

Krapiec, P., M. Milaneza \& F. Pires. 2003. Effects of different combinations of growth reguladors for bud induction from seedlings of Cattleya walkeriana Gardner (Orchidaceae). Acta Scientiarum: Biological Sciences. Maringá, 25(1): 179-182. Brasil

León, M. 1995. Conservación de especies peruanas de orquídeas utilizando la técnica de cultivos in vitro. Tesis para optar el título de Biólogo. Universidad Agraria La Molina. Lima. Perú

Martinez, E. 2002. Citoquininas y fitocromos. VIII
Simposio. Metabolismo y modo de acción de Fitohormonas. Edit. Junta de Andalucía: Consejería de Agricultura y Pesca. Sevilla. España. pag. 173182

Mauro, M. 1994. Influence of bencilaminopurine and alpha-naphthaleneacetic acid on multiplication and biomass production of Cattleya aurantiaca shoot explants. Lindleyana, West Palm Beach, 9: 169-173.

Morel, G., 1974. Clonal multiplication of orchids. In: C.L. Withner (ed.), The Orchids: Scientific Studies, pp. 169-222. Wiley, New York.

Murashige, T. \& F. Skoog. 1962. A revised medium for rapid growth and bioassays with tobacco tissues cultures. Physiol. Plant. 15: 473-497.

Nagaraju V. \& S. K. Mani. 2005. Rapid In Vitro Propagation of Orchid Zygopetalum intermedium. Plant Biochemistry \& Biotechnology. 14: 27-32.

Nayak N., S. Rath \& S. Patnaik. 1997. In vitro propagation of three epiphytic orchids, Cymbidium aloifolium (L) Sw., Dendrobium aphyllum (Roxb.) Fish. and Dendrobium moschatum (Buch-Ham) Sw. through thidiazuron - induced high frecuency shoot proliferation. Scientia Horticulturae 71: 243-250.

Peres, L., N. Majerowicz \& G. Kerbauy.2001. Dry matter partitioning differences between shoots and roots in two contrasting genotypes of orchids and their relationship with endogenous levels of auxins, cytokinins and abscisic acid. Revista Brasileira de Fisiologia Vegetal, 9: 169176.

Peterson, R.L, Y. Uetake \& C. Zelmer. 1998. Fungal symbioses with orchid protocorms. Symbiosis 25: 29-55.

Pierik, R. 1990. Cultivo in vitro de plantas superiors. Editorial Mundi Prensa. Madrid.

Puchooa, D. 2004. Comparison of Different Culture Media for the In Vitro Culture of Dendrobium (Orchidaceae). International Journal of Agriculture \& Biology, 6 (5): 884-888.

Rao, A.N. 1997. Tissue culture in orchids industry. In: Bajaj, Y. P. S., Reinert J. Applied and Fundamental Aspects of Plants, Cell, Tissue and Organ Cultura. Springer-Verlag. Berlin. pp. 44-69.

Rasmussen, F. 1985. In The families of monocotyledons: Structure, evolution and taxonomy (RM Dahlgrn, H Clifford, PF Yeo, Editors), pp 249.

Salisbury, F. \& C. Ross. 2000. Fisiología de las plantas. Thomson Edited Spain Paraninfo. Madrid.

Teixeira, J. 2003. Thin Cell Technology in ornamental plant micropropagation and biotechnology. African Journal of Biotechnology Vol. 2 (12), pp. 683-691.

Teng W., L. Nicholson \& M. Teng. 1997. Micropropagation of Spathoglottis alicata. Plant Cel 
Report. 16: 831-835.

Tokuhara K. \& M. Mii. 2001. Induction of embryogenic callus and cell suspension culture from shoot tips excised from flower stalk buds of Phalaenopsis (orchidaceae). In Vitro Cell. Dev. Biol. Plant 37: 457-461.

Torres J. \& N. Mogollón. 2000. Micropropagación de
Cattleya mossiae Parker ex Hook mediante brotación axilar inducida por tidiazurón. Bioagro 12(1): 10-14.

Young P., H.N. Murthy \& P. Yoeup. 2000. Mass multiplication of protocorm-like bodies using bioreactor system and subsequent plant regeneration in Phalaenopsis. Plant Cell, Tissue and Organ Culture 63: 67-72.

Carlos Enrique Condemarín Montealegre, Biólogo, es Asistente del Laboratorio de Fisiología y Cultivo de Tejidos Vegetales de la Universidad Nacional de Trujillo, Perú.

Julio Chico Ruíz es Master en biotecnologíay Profesor de Fisilogía y Biotecnología Vegetal en la Universidad Nacional de Trujillo, Perú.

Claudia Vargas Arteaga es Asistente del Laboratorio de Fisiología y Cultivo de Tejidos Vegetales de la Universidad Nacional de Trujillo, Perú. 